\title{
LA PERVIVENCIA DEL \\ ESTOICISMO SENEQUISTA EN LAS PAREMIAS ESPAÑOLAS
}

\author{
Xavier Pascual-López ${ }^{1}$ \\ https://doi.org/10.18778/8220-421-6.06
}

\begin{abstract}
The Stoic doctrine of Seneca was assimilated in the Middle Ages and in the Renaissance by Christianity and Humanism, which made it one of the basic references of ancient culture. In addition, in the Spanish sphere it was adopted as an anachronistic reference of Hispanicness. Both factors favoured the wide diffusion of his works at the time in which the Spanish proverbs were forged. The aim of this chapter is to trace Seneca's reception in Spanish proverbs, especially those regarding self-control, how to deal with the vicissitudes of fortune, the capacity for moral improvement, and how virtue is the key to achieving happiness.
\end{abstract}

Keywords: proverb, Stoicism, fortune, Lucius Anneus Seneca, Classical tradition.

Palabras clave: paremia, estoicismo, fortuna, Lucio Anneo Séneca, tradición clásica.

1 Universidad Adam Mickiewicz de Poznań, Facultad de Filologías Modernas, Instituto de Filología Románica, al. Niepodległości 4, 61-874 Poznań, Polonia,xavpas@amu.edu.pl 


\section{Introducción}

Cuando un hablante recurre a una paremia ${ }^{2}$ como, por ejemplo, No hay mal que cien años dure, sabe que está recurriendo a modos de hablar formularios que se han ido convencionalizando a lo largo de los tiempos y que se le presentan en la mente de manera automatizada; sin embargo, no suele ser consciente de que su uso conlleva que el contenido de su discurso se amolda a unas formas de pensar y de valorar la realidad que están presentes en dicha paremia, la cual se inscribe en una tradición textual generalmente muy extensa en la que se funden las vías culta y popular. A pesar de que comúnmente las paremias (especialmente, los refranes) se han entendido como la cristalización de la voz del pueblo y de la sabiduría popular, las fuentes de las que beben muchas de ellas pueden remontarse a la Antigüedad clásica, o bien al menos pueden presentar ideas que también nos han llegado a través de la tradición escrita a modo de loci communes que recorren la filosofía y la literatura.

En estas páginas nos centraremos en las huellas del pensamiento estoico del filósofo romano Lucio Anneo Séneca en el acervo paremiológico español. La elección de Séneca no es fortuita, puesto que nuestra hipótesis de partida es que su influencia es destacada debido a varios factores: el carácter moralizante de su obra (que concuerda con la índole de gran parte de las paremias), la popularidad de Séneca entre los filósofos hispanos, la amplia difusión de su doctrina en la Edad Media y en el Renacimiento (Mayer, 2015), épocas en las que se crean y se fijan la mayoría de

2 Debido a la heterogeneidad de nuestro corpus, adoptamos este término ya ampliamente aceptado en los estudios lingüísticos a partir de lo establecido por Corpas Pastor (1996: 132-133), según la cual las paremias son unidades fraseológicas con autonomía textual y significado referencial, de manera que bajo este hiperónimo se incluyen expresiones pluriverbales tradicionalmente conocidas como refranes, proverbios, sentencias, máximas, adagios, aforismos, apotegmas, etc. (denominaciones sin un claro fundamento lingüístico). 
las paremias de las lenguas modernas; y, por último, la adopción de su filosofía moral por parte del Cristianismo (Torre, 2015), el cual -a su vez- actúa como filtro ideológico que favorece la consolidación de unas paremias frente a otras.

Los vestigios de Séneca en nuestras paremias pueden observarse tanto mediante la adaptación al español de paremias (o unidades posteriormente proverbializadas) presentes en sus obras, como a través de la existencia de unidades susceptibles de ser entendidas como herencia de las ideas del pensador estoico. Si bien es cierto que esta "continuidad" a veces puede ser polémica, creemos que no deja de ser revelador que sea posible establecer estos vasos comunicantes entre las consideraciones senequistas y las paremias españolas ${ }^{3}$.

\section{2.}

\section{El racionalismo estoico}

A grandes rasgos, el estoicismo parte de una concepción del mundo como una especie de mecanismo de relojería en el que cada hecho surge y deriva del anterior gracias a un orden lógico y racional que se revela a guisa de designio divino, de modo que se ha establecido providencialmente como el mejor de todos los órdenes posibles (Sellars, 2006: 99-101). El ser humano es capaz de captar algunos trazos de este orden, pero no todos, de manera que aquello que considera malo es sencillamente algo que escapa a sus capacidades epistemológicas para aprehender la totalidad del plan divino. Pese a lo limitado de la naturaleza humana, su inteligencia le permite entender que forma parte de una estructura superior $y$, por ende, desde el punto de vista ético, debe acomodar su conducta al mismo. En consecuencia, comprender la naturaleza y la organización del cosmos es esencial para la adquisición de la sabiduría,

3 Debido a las limitaciones de esta publicación, estos vestigios senequistas en las paremias españolas no se presentarán de forma exhaustiva, sino que se pretende presentar los ejes básicos de la ética estoica de Séneca y sus implicaciones paremiológicas. 
la valoración del bien, el ejercicio de la virtud y, en última instancia, la consecución de la felicidad (Long, 2001 [1996]: 134; Brun, 1997: 105; Sellars, 2009 [2003]: 57; Cardona, 2015: 35).

Por tanto, "[t]he goal for the Stoic should be the self-perfection of the sapiens" (Star, 2016: 32), ya que mediante este perfeccionamiento moral podrá protegerse de las pasiones, por cuya irracionalidad son incompatibles con la virtud y la felicidad (Cardona, 2015: 66). Séneca se hace eco de esta idea de que el ser humano puede aprender, puesto que "nemo nascitur sapiens, sed fit" ("nadie nace sabio, sino que lo llega a ser', Ira 2.10.6), cita con la que se corresponden diversas paremias españolas (Nadie nace enseñado, 56746 ${ }^{4}$. Ninguno nace maestro, 31997. Nadie es sabio por lo que supo su padre, 56745. Nadie nació sabiendo, 56747. En la cuna, sabiduría ninguna, 56748). En otro pasaje, Séneca alude a una paremia preexistente al respecto: "Tamdiu discendum est, quamdiu nescias; si proverbio credimus, quamdiu vivas" ('Debes aprender mientras ignores; si creemos en el proverbio, mientras vivas'). Aunque la paremia no ha pervivido en español, sí tenemos la convicción de que siempre se puede aprender (Para aprender, nunca es tarde, 4881. Para aprender, siempre hay tiempo, 4882), porque "etiam seni esse discendum" (Ep. 76.3: 'también hay que aprender de viejo, Ep. 17.6), asociación presente en numerosas paremias españolas (Para aprender y tomar consejo, nunca se es viejo, 4883. La vieja que de vieja se moría, cada día cosas nuevas aprendía, 4901. Muriéndose Salomón, tomaba nueva lección, 4905. Salomón, que tanto sabía, de los niños aprendía, 4908. Siempre es el hombre estudiante, y muere ignorante, 32002. Más vale aprender viejo que morir necio, 4880. Más vale viejo a la escuela que necio a la huesa, 63467).

Este aprendizaje, que en las paremias españolas se presenta de forma general, en la filosofía estoica se concretaba en aprender a dominarse a sí mismo, venciendo las pasiones que socaban la racionalidad y la integridad del ser humano. A este respecto,

4 Las paremias españolas proceden de Martínez Kleiser (1953) y junto a cada una de ellas se indica la numeración con la que pueden encontrarse en esta obra. 
Séneca asevera que "potentissimus est qui se habet in potestate" ('el más poderoso es el que es dueño de sí mismo', Ep.90.34), de modo que "imperare sibi maximum imperium est" ('gobernarse a sí mismo es el máximo gobierno', Ep. 113.30). Estas ideas perviven en paremias que ensalzan a quien así se comporta (No es poco rico el que es dueño de sí mismo, 19590. Quien a sí mismo se vence, ése es el más valiente, 63426. Quien a sí vence, a nadie teme, 63427), equiparando dicha victoria sobre uno mismo con una gran gesta (Quien se vence a sí mismo, a cien gigantes juntos ha vencido, 63424. Saber vencerse es gran saber, mayor que a moros vencer, 63425. Haz cuenta si te vences de que a todo el mundo vences, 63423) porque, al fin y al cabo, es la mayor de las victorias (No hay mejor victoria que vencerse el hombre a sí,63419. El mayor vencimiento es vencerse uno a sí mismo, 63420. Mayor vencimiento es el propio que el ajeno, 63421); por el contrario, se menosprecia a quien no lo hace (Quien no es dueño de sí, no es dueño de nada, 63428. No vence quien a sí no [se] vence, 63429).

En la práctica, este dominio sobre sí mismo, este control de las emociones conducirá a un ideal de impasibilidad e imperturbabilidad que salvaguardará la serenidad racional del sabio especialmente en dos contextos: ante los reverses de la fortuna y ante la tentación de los placeres (Sellars, 2006: 102).

\section{3.}

\section{Actitud ante las vicisitudes de la fortuna}

Epicteto (Ench. 8) establece el dogma estoico de que para tener una vida satisfactoria no hay que intentar que las cosas ocurran como quieres, sino aceptarlas tal como ocurren, en vistas de que responden a la voluntad de ese cosmos regido por la providencia divina. "In Stoic physics, the individual is understood as but one component within a cosmos conceived as a complex network of interconnected causes. This network of causes was called «fate»" (Sellars (2009 [2003]: 137). Para Epicteto y los demás estoicos, casi toda la miseria humana es consecuencia de no entender esta interconexión y no aceptar el hado, sino creer que se tiene el control 
sobre las cosas y fundar la felicidad en aspectos externos que en realidad están fuera de nuestro alcance, lo cual nos hace vulnerables a las vicisitudes de la fortuna. En cambio, lo adecuado sería basar la felicidad en lo que verdaderamente depende de nosotros y no se nos puede arrebatar (Sellars, 2006: 17).

En esta línea, Séneca advierte de que "nihil dat fortuna mancipio" ('la fortuna nada da en propiedad', Ep. 72.7), de modo que "non est tuum fortuna quod fecit tuum" ('no es tuyo lo que la fortuna ha hecho tuyo', Ep. 8.10). Algunas paremias españolas aleccionan sobre lo mismo (Lo que te ha tocado por suerte, no lo tengas por fuerte, 59490. ¿A qué tanto orgullo, si aquí nadie tiene nada suyo?, 47684), porque la fortuna al fin se lleva lo que trae (Lo que el día trae, el día se lo lleva, 9022. Cuando la fortuna se va, sólo lo que ella trajo se puede llevar, 16624).

Contra la inconstancia de la fortuna también nos previene Séneca (Thyes. 596-597): "Nulla sors longa est: dolor ac voluptas / invicem cedunt" ('Ninguna suerte es prolongada: el dolor y el placer se suceden alternativamente'). En español hallamos tanto la idea de que ambos -el dolor y el placer-son breves (No hay mal que cien años dure, ni bien que a ellos ature, 9096. No hay bien que cien años dure, ni mal que a ellos allegue, 7317. No hay mal ni bien que dure años cien, 9106. Males y bienes, ellos se van y ellos se vienen, 9101. Ni el bien es eterno, ni el mal duradero, 9104), como que se suceden rápidamente (Bienes y males son ambulantes: hoy están aquí y mañana en otra parte, 9100. Mal tras bien, de seguro bien, 9095. A tres días buenos, cabo de mal estreno, 13396. Pena y alegría, a veces en un mismo día, 9053. Al reír y al llorar, uno tras otro los vi andar, 2521. Risa y llanto, andan por el mundo alternando, 2522. Tras mucho reír, mucho llorar suele venir, 9066. Cuando la alegría a la sala llega, el pesar va subiendo por la escalera, 9074. Aqui fortuna ordena que donde tuve el placer tenga la pena, 9059). De hecho, la alternancia es tal que puede interpretarse que "ipsae voluptates in tormenta vertuntur" ('los mismos placeres se convierten en tormentos', Ep. 24.16), es decir: No hay placer que pena no venga a ser (50555).

En cuanto a qué dura más, si el placer o el dolor, Séneca por un lado proclama que "brevior voluptas" ('el placer es más corto', 
Thyes. 597), pero por otro sostiene sentenciosamente que "nullus dolor longus est qui magnus est" ('ningún gran dolor es duradero', Ep. 30.14). En este caso, las paremias españolas se decantan notoriamente por la primera versión (Eso tiene malo lo bueno: que se acaba presto, 9094. A placeres breves, dolores nada leves, 50546. A placer pasajero, dolores años enteros, 50547. El deleite presto se acaba, 50564. Placer y alegría, tan presto se va como se venía, 9085. Alegrías y placeres, tan prestos se van como se vienen, 9086), revelándose así ese talante pesimista del refranero español descrito por Armando de Miguel (2000: 37-38):

Lo fundamental es el sentimiento de disgusto respecto a la realidad que se percibe o la que se avizora. Las más de las veces se trata de un pesimismo estudiado, esto es, un tanto afectado o preparado deliberadamente para prevenir los eventuales quebrantos. Es la reacción natural de un pueblo viejo y doliente, que ha tenido que sobrevivir a continuas calamidades.

Si bien es verdad que muchas paremias se centran en la desaparición del placer, también es cierto que localizamos refranes -más minoritarios- que ponen énfasis en el fin del dolor (Día vendrá que el que hoy llora cantará, 9067. Tiempo vendrá en que el triste se alegrará, 9083. No hay pesar que no se vaya, 9087. Cuando mayor mal vien, cerca está el bien, 9093. Sufra quien penas tiene, que un tiempo tras otro viene, 48106. Sufrir convién; que tras el mal viene el bien, 48107). En esta línea más positiva también hallamos una paremia utilizada por Séneca (Quaest. nat.7.9.3): Nulla tempestas magna perdurat ('Ninguna gran tempestad perdura'), que cuenta con equivalentes que recurren a la misma metáfora (No hay tempestad que mucho dure, 16873. No hay nublado que dure un año, 16872. La furiosa borrasca, pronto pasa, 16875. El día ñublo, vase como el humo, 9021. A mucho llover, esperar; que de fijo ha de escampar, 22831. Siempre que llueve escampa, 22833. Tras la tempestad viene la calma, 8986).

Sin embargo, como si quisiera darnos una de cal y otra de arena para que seamos conscientes de la ligereza de la fortuna, también nos recuerda la siguiente sentencia: Non semper Saturnalia 
erunt ('No siempre serán Saturnales', Apoc. 12.2). En español, estas fiestas han sido adaptadas de numerosas maneras, haciendo que las paremias resulten más cercanas a la realidad de los hablantes. Si partimos del genérico No todos los días son fiestas (9082), estas pueden concretarse en festejos paganos como la vendimia (No es cada día agosto ni vendimia, 17729), el Sabbat en una paremia judeoespañola (Cada día no es sábado, 17727) o diferentes festividades dentro del Cristianismo (No es cada día Pascua ni Santa María, 17730. Capa negra y cofradía, no puede ser cada día, 17728. No hay carnaval sin cuaresma, 9080. No hay Domingo de Ramos sin Viernes Santo, 9081).

Una vez establecida la desconfianza respecto a la fortuna, el sabio estoico se fijará una norma de vida: la apatheia, la impasibilidad que deriva de la correcta comprensión del orden del mundo y con la que se consigue la eliminación de las pasiones, alcanzando así la serenidad de ánimo necesaria para conseguir la felicidad (Graver, 2007: 210; Star, 2016: 30). Una de las más conocidas formulaciones de este ideal nos ha llegado de las manos de Séneca (Cons. Helv. 5.1): "Nec secunda sapientem evehunt nec adversa demittunt" ('Al sabio ni la prosperidad lo ensoberbece, ni la adversidad lo abate'). Su posterior proverbialización se hace evidente al examinar las paremias españolas equivalentes ( $\mathrm{Al}$ sabio, ni el bien lo aloca ni el mal lo apoca, 56738. Ni riqueza te ensoberbezca, ni te abata la pobreza, 32398. Ni te abatas por pobreza, ni te ensalces por riqueza, 32397. Modesto en la prosperidad, y cuerdo en la adversidad, 31873. Si cazares, no te alabes; si no cazares, no te enfades, 10218).

¿Y cómo conseguir esta impasibilidad? La clave está en resignarse y ejercitarse en la capacidad de padecer sin alterarse, es decir, la paciencia en su sentido primario. De este modo, Séneca (Ep. 107.9) tiene claro que "optimum est pati quod emendare non possis" ('lo mejor es soportar lo que no puede remediarse'), al igual que varias de nuestras paremias (Lo que no se puede remediar, se ha de aguantar, 48093. Lo que no se puede mudar, sufrirlo has, 48094. A lo que no puede ser, paciencia, 48081. Donde no hay remedio, haya paciencia, 48095). Asimismo, en su obra De ira (3.16.1), Séneca considera que "unum est levamentum malorum 
ingentium pati et necessitatibus suis obsequi" ('hay un solo alivio para las grandes desgracias: sufrirlas y prestarse a sus exigencias'). Esta radical actitud se formuló mediante la máxima Sustine et abstine ('Sufre y abstente', Erasmo, Adag. 2.7.13), que es la fuente directa de diversas paremias españolas (El bueno sufre y sostiene, que el malo no puede, 48105. Mientras el mal persevera, sufre y espera, 48115. Cuando la adversidad venga, sufre y espera, y suceda al cabo lo que Dios quiera, 48140. A quien esperar y sufrir puede, todo en su tiempo le viene, 48177. Sufra quien penas tiene, que un tiempo tras otro viene, 48106. Sufrir y callar, y mejor tiempo esperar, 48110. Sufre callando lo que no puedes remediar hablando, 8780. Sufre y vivirás vida de paz, 48112).

\section{4. \\ La voluntad en el ejercicio de la virtud y la consecución de la felicidad}

A pesar de lo ineludible del destino y la aparente impotencia del ser humano ante los avatares de la fortuna, el estoicismo de Séneca se distingue un tanto del de otros filósofos por cuanto se centra en aquello que está en manos del sabio, en relación con su ya mencionada capacidad para aprender. Al decir de Rodríguez Santidrián (2005: 16),

[e]n contraposición a Marco Aurelio, que sometía la ética al logos de Zenón, Séneca carga los rasgos personalistas del vir fortis, habla de superar el destino e incluso la naturaleza. Presenta la vida del sabio más como un combate, en el que es vergonzoso ser derrotado, que como un descubrimiento de la verdad.

Para Séneca, la clave para poder prosperar moralmente reside en la voluntad, de manera que el concepto de voluntas se hace esencial en su doctrina. Inwood (2008: 117-118) señala que a menudo se ha apuntado que en ello radica la originalidad de Séneca dentro del estoicismo, puesto que su voluntarismo romano se opone al intelectualismo predominante en la filosofía griega. Con 
todo, el autor considera un tanto simplista esta oposición y estima que la aportación de Séneca al concepto de voluntas es su énfasis en el ejercicio de la mente para lograr "self-control, self-awareness, and self-shaping" (Inwood, 2008: 123).

A este respecto, Séneca afirma que "nihil est tam difficile et arduum quod non humana mens vincat" ('no hay nada tan difícil y arduo que no venza la mente humana', Ira, 2.12.3). La misma idea se encuentra en algunas paremias españolas (Al cuerdo y hábil, todo le es fácil, 29238), pero en la mayoría la alusión racionalista a la mente -propia del estoicismo y de la filosofía- se ha visto sustituida por el término corazón, cuyo papel en la filosofía antigua se limita a ser el motor de la vida física o a mediar entre la razón y las pasiones (Herrero, 1999: 73-74), mientras que en épocas posteriores pasó a asociarse con el deseo y la voluntad, que es el sentido con el que lo vemos en nuestras paremias (Buen corazón quebranta mala ventura, 21494. Corazón fuerte quebranta cativa suerte, 21495. El corazón fuerte a la desgracia vence, 21496).

El poder de la voluntad se hace evidente cuando sostiene que "magna pars est profectus velle proficere" ('la mayor parte del progreso es querer progresar', Ep. $\left.71.36^{5}\right)$. Esta consideración aparece con profusión en el refranero (El solo querer, es medio poder, 64856. En el hombre, querer, poder y hacer, 64854. Más es querer que poder, 64857. Más hace el que quiere que el que puede, 64855. Querer es poder, 64858. Quien quiso, hizo, 64863. Quiere, y podrás; porfía, y vencerás, 64865. Bástale querer a quien no logra poder, 64870). Como vemos, tanto Séneca como las paremias nos dan esperanza amparándose en la noción de que la voluntad es el camino para vencer las dificultades de la vida. Por tanto, Séneca nos insta a enfrentarnos a lo que se nos presente, pues "multa non quia difficilia sunt non audemus, sed quia non audemus sunt difficilia" ('no es que no intentemos muchas cosas porque son difíciles, sino que son difíciles porque no las intentamos', Ep. 104.26) o, como

5 Cf. "pars magna bonitatis est velle fieri bonum" ('la mayor parte de la bondad es querer hacerse bueno', Ep. 34.3). 
dice el refrán español, No hay mayor dificultad que la poca voluntad (18019) 6 .

El archiconocido proverbio acuñado por Virgilio (Aen. 10.284) Audentes fortuna iuvat ('La fortuna ayuda a los atrevidos') no solo lo citó literalmente Séneca (Ep. 94.287), sino que también lo adaptó conforme a su concepción del vir fortis y al poder de la voluntad: "Fortuna fortes metuit, ignavos premit" ('La fortuna teme a los fuertes y oprime a los pusilánimes', Med.159). Este elogio de la osadía unido al denuesto de la pusilanimidad impregna nuestro refranero (La fortuna al temeroso desprecia y al osado ayuda, 5686. El mundo es para los osados; no para los tímidos y callados, 5683. A los que se atreven, les ayuda la suerte; y a los que no, los deja para quien son, 5678. Para el cobarde, o no hay buena suerte, o le llega tarde, 10980. A quien irresoluto anda, fortuna le vuelve la espalda, 62099. La fortuna ayuda a los osados, 59370. Dios desprecia a los cobardes, 10977. Al hombre osado, la fortuna le da la mano, 5675. A quien se aventura, Dios le ayuda, 5680).

En realidad, Séneca concibe la adversidad como una ocasión para ejercitarse en la virtud, dado que "marcet sine adversario virtus" ('la virtud se marchita sin adversario', Prov. 2.3) y, a su vez, "this virtue is the only thing that can bring us genuine happiness" (Sellars, 2006: 114). Para tener una visión general de este razonamiento, podemos citar algunos pasajes del capítulo 4 de De providentia:

La virtud tiene querencia de los peligros y pone los ojos en el camino que lleva y no en lo que ha de sufrir, pues es parte de su gloria mucho de lo que ha de padecer. [...] Os pido, por favor, que no os atemoricen aquellas pruebas que los dioses inmortales ponen como estímulos al alma. La adversidad es ocasión de virtud. [...] Que todos aquellos a quienes se mandan pruebas,

6 Cf. No hay cosa que hecha sin voluntad no parezca dificultosa, 10931. A buena voluntad nunca falta facultad, 64868. No falte voluntad, que no faltará lugar, 64867.

7 "Audentes fortuna iuvat, piger ipse sibi opstat" ('La fortuna ayuda a los atrevidos, el perezoso se estorba a sí mismo’). 
que sólo a los medrosos y cobardes hacen llorar, digan lo mismo: «Dios nos ha juzgado dignos de experimentar en nosotros todo lo que la naturaleza humana puede padecer». [...] La fortuna nos azota y nos lacera: sufrámosla. No es crueldad, es lucha: cuantas más veces vayamos a ella, más fuertes seremos. [...] Por la paciencia llega el alma a despreciar el poder de los males. [...] Nada causa desventura, nada es mísero, cuando la naturaleza lo ha convertido en costumbre, pues con el andar del tiempo llegan a causar placer aquellas molestias que comenzaron por necesidad. [...] Mucho aprovecha, por tanto, a los hombres buenos para que nada les intimide, moverse entre tribulaciones y soportar con ecuanimidad las cosas que no son de suyo males, sino para los que las sufren mal (ed. Rodríguez Santidrián, 2005: 40-43).

Al hilo de estas disquisiciones sobre el poder purificador de la adversidad, un poco más adelante el propio Séneca afirma con carácter sentencioso: "Ignis aurum probat, miseria fortes viros" ('El fuego prueba el oro; la miseria, a los hombres fuertes', Prov. 5.10). Pese a que este tipo de consideración que ensalza las estrecheces desde un punto de vista moral choca-como veremos más adelante-con numerosas paremias españolas, encontramos algunas equivalentes a la cita de Séneca, con la misma imagen en torno al oro (En la piedra se prueba el oro, y el hombre, en el oro, 34148. Con el toque se prueba el oro, y el hombre, con plata y oro, 16992. El oro se prueba en el toque, y en el oro, el hombre, 34147. El oro, en la piedra; y el hombre en la moneda, 34146. El toque del oro, $y$ del hombre el tesoro, 53424. El oro y el hombre, tocando se conoce, 53426).

¿Cómo conseguir, entonces, esa ecuanimidad anímica que permite que el ser humano afronte la adversidad con virtud? Para Séneca está claro que "magni animi est magna contemnere, ac mediocria malle quam nimia" ('es propio de una gran alma desdeñar lo grande y preferir lo moderado a lo excesivo', Ep. 39.4). Y es que, de acuerdo con el estoicismo, "vitiosum est ubique quod nimium est" ('está viciado en todas partes lo que es excesivo', Tranq. an. 9.6), idea reflejada profusamente en las paremias españolas 
(Todo lo excesivo es vicioso, 23475. Todos los extremos son viciosos, 23748. Lo demasiado, siempre ha dañado, 23470. Lo demasiado causa empacho/enfado, 23467-8. Toda demasía enfada y hastía, 23474. De lo mucho, poco; y de lo poco, nada, 41956. De todo algo/ un poco y de nada mucho, regla es de hombre ducho, 41957-9. Nada en demasía, ni en la tristeza ni en la alegría, 23473).

Por tanto, la conclusión lógica es que "omnis in modo est virtus" ('toda virtud consiste en la moderación', Ep. 66.9). En español la moderación se relaciona igualmente con la virtud (En el medio consiste la virtud, 60382. Todo extremo es vicioso; sólo el medio es virtuoso, 60379), pero también sencillamente con lo deseable (El medio es lo mejor, 60371. El mejor remedio es procurar siempre el medio, 54930. Busca el medio en todo, y tendrás buen acomodo, 60372. Busca en todo el medio, que es lo bueno, 60373. Todos los medios son buenos, y malos todos los extremos, 60380) o con lo razonable (Quien tiene seso, para todo tiene medida y peso, 13627. Mesura es cordura, 41964. El buen seso huye de todo exceso, 41941).

A ojos de Séneca, este elogio de la moderación es acorde con el orden cósmico y con la naturaleza, caracterizada por el equilibrio que le da la providencia divina, de modo que "exiguum natura desiderat, opinio immensum" ('la naturaleza desea poco; la imaginación, muchísimo', Ep. 16.8). De la misma falta de concordancia entre lo necesario y lo deseado advierten nuestras paremias (La naturaleza con poco se contenta, 45161. A la naturaleza con poco le basta; pero el hombre no se harta, 33867. La naturaleza pide poco, y mucho el hombre loco, 33868).

En consecuencia, el ideal de pobreza y austeridad se hace presente como estilo de vida en el pensamiento senequista: "si vis vacare animo, aut pauper sis oportet aut pauperi similis" ('si quieres cultivar el espíritu, tienes que ser pobre o semejante al pobre', Ep. 17.4); y este camino virtuoso es el que lleva a la felicidad, puesto que "in virtute posita est vera felicitas" ("la verdadera felicidad está en la virtud', Vit. beat. 16.1). Aunque, como hemos visto, la continuidad entre Séneca y nuestras paremias es generalmente muy productiva, en esta ocasión el elogio de la austeridad topa con el pragmatismo del refranero español, que está más arraigado 
en el día a día y suele rechazar las asociaciones entre la pobreza y la felicidad ${ }^{8}$. Con todo, encontramos algunas paremias que las hermanan (A Dios, el sabio pedía pobreza con alegría, 51098. Pobreza y alegría pido a Dios y a Santa María, 51099. Canta la rana, y no tiene pelo ni lana, 51097) y otras, todavía menos numerosas, que supeditan la alegría a la virtud (La alegría la da la conciencia limpia, 2375. Haz bien, y vive alegre, 7502. Quien vive bien, espere bien, 64623. Si eres clemente, serás feliz siempre, 7565).

Respecto a esta escasez, podríamos entender que algunas paremias que, aparentemente, podrían vincularse por tradición textual con la aseveración senequista paralela de que "quam bene vivas refert, non quamdiu" ('lo que importa es cuán bien vivas, no cuánto tiempo', Ep. 101.15) en realidad han sufrido un desplazamiento semántico, dado que la concepción moralista de ese "vivir bien" que observamos en Séneca", en la que "bien" se refiere a lo virtuoso, ha adquirido un sentido mucho más hedonista en las paremias españolas (Quien de vivir bien no se olvida, vive largos días, 42007. La vida, larga o corta, que sea buena es lo que importa, 31444 . Vivir bien es lo que importa; que la vida es corta, 63495), de modo que casi se convierten en un canto al tópico del Carpe diem.

\section{5.}

\section{Consideraciones finales}

En la adopción de Séneca por parte del Humanismo y del Cristianismo estriba la trascendencia de su influencia en el mundo occidental. En el caso de la cultura española, el hecho de haber nacido en la Península favoreció su anacrónica consagración

8 Por ejemplo, La pobreza tiene por amiga a la tristeza, 51104. En la casa do no hay qué comer, todos lloran y no saben de qué, 51107. Donde no hay qué comer, no hay placer, 51112.

9 También en otros pasajes de su obra: "Non vivere bonum est, sed bene vivere" ('No es bueno vivir, sino vivir bien', Ep. 70.4), "Quomodo fabula, sic vita; non quam diu, sed quam bene acta sit refert" ('La vida es como una obra teatral; lo que importa no es la duración, sino lo bien que se haya representado’, Ep. 77.20). 
como "español”, puesto que fue apócrifamente asimilado como uno de los precursores del espíritu español, erigiéndose en lo que los estudios culturales han dado en llamar un "santo cultural". Ambos factores - uno de carácter más general, otro de índole más nacional-favorecieron la difusión de sus obras, ya fuera en forma íntegra, ya a guisa de excerpta o antología. Lo que resulta evidente es que toda una serie de fragmentos de su obra -especialmente aquellos que ya tenían un carácter sentencioso- llegaron a proverbializarse y circular a modo de citas, hasta el punto de que las palabras de Séneca se convirtieron en sinónimo de "perlas de sabiduría"10.

Como consecuencia de esta circulación, muchas de las paremias latinas a las que dio origen se adaptaron al español, pasando a engrosar nuestro acervo paremiológico. A su vez, el propio refranero, caracterizado por su creatividad, renovó estas primeras paremias, innovó sobre su forma, manteniendo generalmente su contenido fiel a la fuente senequista original ${ }^{11}$. Como hemos visto en estas páginas, generalmente son diversas y variadas las unidades que podemos considerar que entroncan con las obras de Séneca, siendo -debido a su heterogeneidad- una lúcida muestra de cómo lo culto y lo popular conviven y fluctúan en nuestras paremias.

En cuanto a la proliferación de estas paremias de herencia senequista, vemos que son mucho más abundantes aquellas que se centran en lo más inmediato, en lo que atañe directamente al día a día del ser humano, es decir, el dolor y el placer causados por los reveses de la fortuna, así como las paremias centradas en el "yo", en el poder de la voluntad de cada cual. En contraposición, las elucubraciones en torno a la virtud y al dominio de uno mismo son menos productivas, seguramente por tratarse de temas que son objeto de reflexiones filosóficas (o religiosas) más elevadas y más bien ajenas a la cotidianidad de los hablantes. Y es que

10 No en vano la muy difundida colección apócrifa Proverbia Senecae le fue atribuida, pese a que en su mayoría -como es bien sabidoeran las Sententiae procedentes de los mimos de Publilio Siro.

11 Salvo excepciones como en los últimos casos mencionados. 
aunque vía culta y popular convivan, es esta última la que se caracteriza por una expresividad que lleva necesariamente a la creatividad lingüística, a un ejercicio de repetición e innovación constante de esas paremias supuestamente fijadas, pero obviamente sujetas a variación.

\section{Bibliografía}

Brun, J. (1997): El estoicismo [trad. J. Blanco Regueira]. Toluca: Universidad Autónoma del Estado de México.

Cardona, J.A. (2015): Filosofía helenística. Estoicos, epicúreos, cínicos y escépticos. Barcelona: Batiscafo.

Corpas Pastor, G. (1996): Manual de fraseología española. Madrid: Gredos.

Graver, M.R. (2007): Stoicism \& Emotion. Chicago-London: University of Chicago Press.

Herrero, M. (1999): "Voluntad, razón, corazón". Cuadernos de Anuario Filosófico, 73/4: 71-94.

Inwood, B. (2008): “The Will in Seneca the Younger", en: J.G. Fitch (ed.), Seneca (Oxford Readings in Classical Studies). OxfordNew York: Oxford University Press: 114-135.

Long, A.A. (2001 [1996]): Stoic Studies. Berkeley-Los AngelesLondon: University of California Press.

Martínez Kleiser, L. (1953): Refranero general ideológico español. Madrid: Editorial Hernando.

Mayer, R. (2015): "Seneca Redivivus: Seneca in the Medieval and Renaissance World”, en: S. Bartsch \& A. Schiesaro (eds.), The Cambridge Companion to Seneca. New York: Cambridge University Press: $277-288$.

Miguel, A. de (2000): El espíritu de Sancho Panza. El carácter español a través de los refranes. Madrid: Espasa.

Rodríguez Santidrián, P. (ed.) (2005): Séneca. Tratados morales [trad. P. Fernández Navarrete]. Madrid: Austral.

Sellars, J. (2006): Stoicism (Ancient Philosophies). Durham: Acumen Publishing. 
Sellars, J. (2009 [2003]): The Art of Living. The Stoics on the Nature and Function of Philosophy. London-New Delhi-New YorkSydney: Bloomsbury.

Star, C. (2016): Seneca (Understanding Classics). London-New York: I.B. Tauris.

Torre, C. (2015): "Seneca and the Christian Tradition", en: S. Bartsch \& A. Schiesaro (eds.), The Cambridge Companion to Seneca. New York: Cambridge University Press: 266-276. 